\title{
ORIGINAL
}

\section{Marta Słowik \\ The analysis of failure in concrete and reinforced concrete beams with different reinforcement ratio}

Received: 26 February 2018 / Accepted: 4 October 2018 / Published online: 15 October 2018

(C) The Author(s) 2018

\begin{abstract}
In this paper the analysis of failure and crack development in beams made of concrete is presented. The analysis was carried out on the basis of the performed experimental investigation and numerical simulations. A fictitious crack model based on nonlinear fracture mechanics was applied to investigate the development of strain softening of tensile concrete in plain concrete and slightly reinforced concrete beams. The role of strain softening was also discussed according to the inclined crack propagation in highly reinforced concrete beams. The analysis has brought the evidence that the mode of failure in flexural beams varies according to a longitudinal reinforcement ratio. A brittle failure due to the formation of a flexural crack takes place in plain and slightly reinforced concrete beams, and strain softening of tensile concrete is of paramount importance at failure crack initiation and propagation. A stable growth of numerous flexural cracks is possible in moderately reinforced concrete beams, and then the load carrying capacity is connected with reaching the yield stress of reinforcing steel or concrete crushing in the compression zone. In higher reinforced concrete beams without transverse reinforcement, brittle failure can take place due to shear forces and the development of diagonal cracks. However, strain softening of tensile concrete is not the only mechanism influencing the propagation of an inclined crack. Such mechanisms as aggregate interlock and dowel action of steel bars contribute more importantly to the development of failure crack.
\end{abstract}

Keywords Strain softening $\cdot$ Fictitious crack model $\cdot$ Failure process

\section{Introduction}

The load capacity of concrete structures is affected by the cracking behavior of concrete. Since the tensile strength of concrete is much lower than its compressive strength (approximately 10 times), concrete belongs to the group of brittle materials but it is not perfectly brittle. Concrete is considered to be a quasi-brittle material, and therefore, when analyzing the cracking behavior of concrete, not only tensile strength but also tensile toughness is of paramount importance [1]. As a measure of concrete tensile toughness, fracture energy $G_{\mathrm{F}}$ or fracture toughness $K_{\text {IC }}$ can be used [2-4]. However, fracture parameters of concrete have not been applied to the conventional design of concrete structures on the basis of European standards, for example, Eurocode 2 [5].

The paper entitled "The analysis of failure in concrete and reinforced concrete beams with different reinforcement ratio", presented at the ICSID 2017 Conference has been considered for publication in the Special Issue of the Archive of Applied Mechanics Journal (AAM SI ICSID 2017).

M. Słowik $(\varangle)$

Faculty of Civil Engineering and Architecture, Lublin University of Technology, Nadbystrzycka 40, 20-618 Lublin, Poland

E-mail: m.slowik@pollub.pl

Tel.: +48 815384392

Fax: +48 815384390 
Structural members made of concrete are usually reinforced by steel bars. Steel reinforcement is used to resist tension, to distribute cracks and to limit cracks' width. But the first aim of reinforcement is to protect against a brittle failure. When reinforcing steel bars are not designed properly, the structure will crack excessively and may fail. The failure behavior of concrete and reinforced concrete beams under flexure was analyzed by numerous researchers. The analyses were mostly dedicated to typical reinforced concrete beams with longitudinal and transverse reinforcement. Much smaller database of experimental results can be found for longitudinally reinforced concrete beams without transverse reinforcement [6-10]. The performed experimental investigations have shown that the efficiency of longitudinal reinforcement depends on its ratio. Furthermore, the failure process in flexural beams without transverse reinforcement can vary according to the longitudinal reinforcement ratio. The question arises as to what the influence of reinforcement ratio on crack initiation and development is and as to when steel reinforcement effectively protects against brittle, dangerous failure. These problems are discussed in the paper.

\section{Failure analysis of concrete and reinforced concrete beams}

\subsection{Plain concrete and slightly reinforced concrete beams}

The first stage of the scientific research was focused on recognizing the process of the crack's initiation in plain concrete and slightly reinforced concrete beams. The experimental investigation was performed on 3 plain concrete beams and 3 slightly reinforced concrete beams (reinforcement ratio $0.12 \%$ ). Beams were tested in a four-point bending test. The beams were loaded with two concentrated forces which were applied from bottom to top in one third of the span. The application of the upturned way of loading and the loading procedure by forcing displacement allowed to slow down the failure process and to observe crack developing precisely. The loading was realized as deformation controlled using hydraulic jacks with calibrated gauges. The beams were made of normal strength concrete. The quartzite aggregate of the maximum aggregate size $D_{\max }=32 \mathrm{~mm}$ was used to produce the concrete mixture. The basic concrete properties were tested by standard methods. The compressive strength of concrete was tested on 21 cylinders $\phi 150 / 300 \mathrm{~mm}$, and the obtained mean value was $f_{\mathrm{c}}=20.4 \mathrm{MPa}$ (standard deviation $s=2.54 \mathrm{MPa}$ ). The tensile strength of concrete was measured on 21 cubes 150/150/150 $\mathrm{mm}$ at a splitting test. The obtained mean value of splitting tensile strength was $f_{\text {ct,sp }}=1.64 \mathrm{MPa}$ (standard deviation $s=0.18 \mathrm{MPa}$ ), and the axial tensile strength was calculated as $f_{\mathrm{ct}}=0.9 f_{\mathrm{ct}, \mathrm{sp}}=1.48 \mathrm{MPa}$. The modulus of elasticity was measured on 21 cylinders $\phi 150 / 300 \mathrm{~mm}$ and the mean value was $E_{\mathrm{c}}=22118 \mathrm{MPa}$ (standard deviation $s=1927 \mathrm{MPa}$ ). The fracture energy $G_{\mathrm{F}}=83 \mathrm{Nm} / \mathrm{m}^{2}$ was not derived experimentally, but it was calculated using the formula given in Model Code [11]: $G_{\mathrm{F}}=\alpha_{\mathrm{F}} f_{\mathrm{c}}^{0.7}$ (where $\alpha_{\mathrm{F}}=10$ for $D_{\max }=32 \mathrm{~mm}, f_{\mathrm{c}}$ in MPa). In slightly reinforced concrete beams, three steel bars $4.5 \mathrm{~mm}$ in diameter were used and the yield stress of steel was $f_{\mathrm{y}}=275 \mathrm{MPa}$. Beam's geometry and the location of steel bars are presented in Fig. 1.

A brittle character of failure was observed in all tested beams during the experiment, but some differences in failure process were noticed and a higher cracking resistance was obtained in slightly reinforced concrete beams in comparison to that measured in plain concrete beams. In plain concrete beams a brittle, sudden failure was noticed right after the appearance of the first flexural crack. In slightly reinforced concrete beams of the reinforcement ratio $0.12 \%$, the failure was also caused by the main flexural crack but the beams' damage was noticed at higher load level than in plain concrete beams. The failure crack did not propagate as rapidly as in concrete beams, and the destructive process in slightly reinforced concrete beams continued progressively developing two or three cracks. The location of cracks in plain concrete and slightly reinforced concrete beams is presented in Figs. 2 and 3. The photographic documentation of the failure crack in the plain concrete beam A1 and the slightly reinforced concrete beam B1 is presented in Fig. 4.

During the experiment, the applied loads were read from the calibrated gauges which were fixed to hydraulic jacks. In plain concrete beams the following maximum forces were read from the gauges: $5.10 \mathrm{kN}, 5.51 \mathrm{kN}$, $4.45 \mathrm{kN}$, and in slightly reinforced concrete beams the maximum forces reached: $5.59 \mathrm{kN}, 5.44 \mathrm{kN}, 5.21 \mathrm{kN}$. Bending moments were first calculated on the basis of the applied external forces, and then they were increased by bending moments connected with a self-weight of the beams. (The self-weight of the beams could not be omitted in the calculation as its contribution in the total bending moment was approximately $10 \%$.) It was observed that the bending moment which was connected with appearing of the first flexural crack decided of the load capacity of plain concrete and slightly reinforced concrete beams. The average value of cracking moment was $M_{\mathrm{cr}, \mathrm{E}}=5.08 \mathrm{kN} \mathrm{m}$ in plain concrete beams and $M_{\mathrm{cr}, \mathrm{E}}=5.39 \mathrm{kN} \mathrm{m}$ in slightly reinforced concrete 

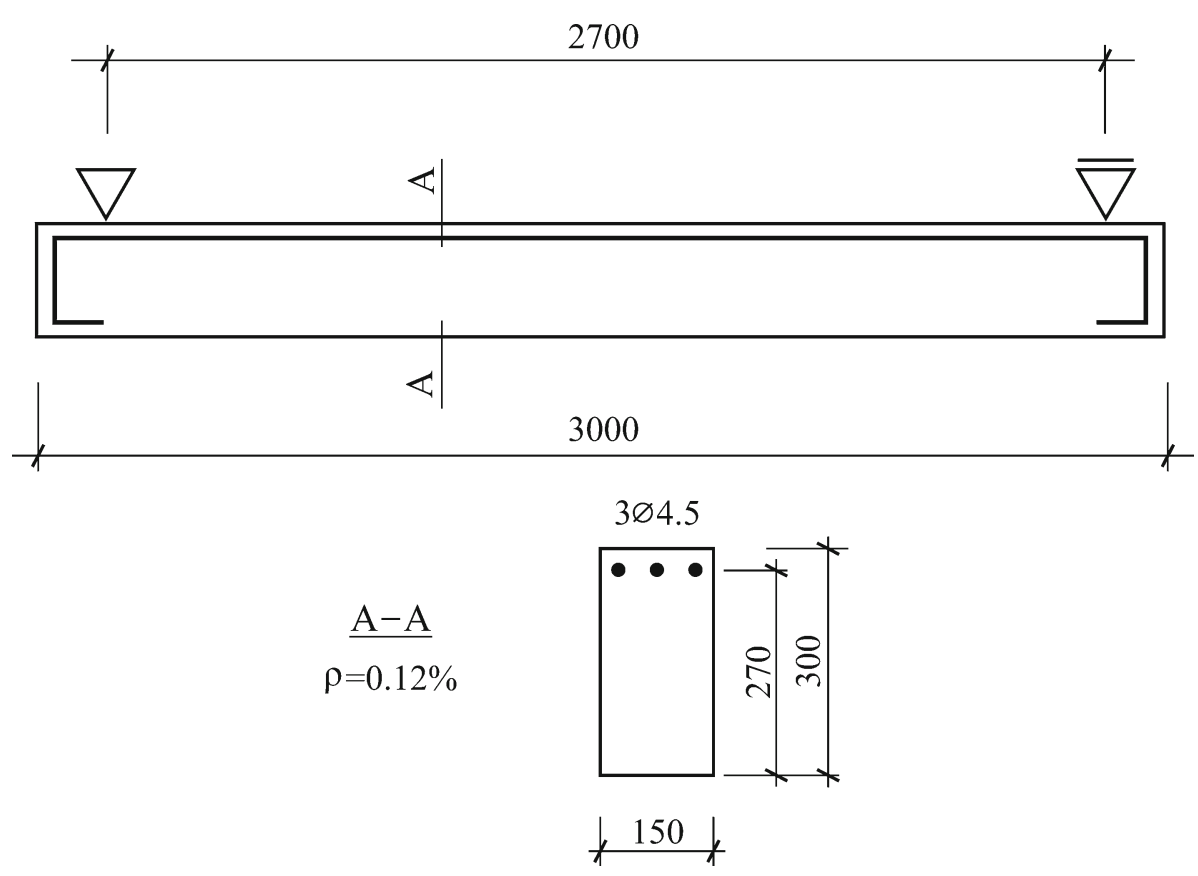

Fig. 1 Beam's geometry and the location of reinforcement
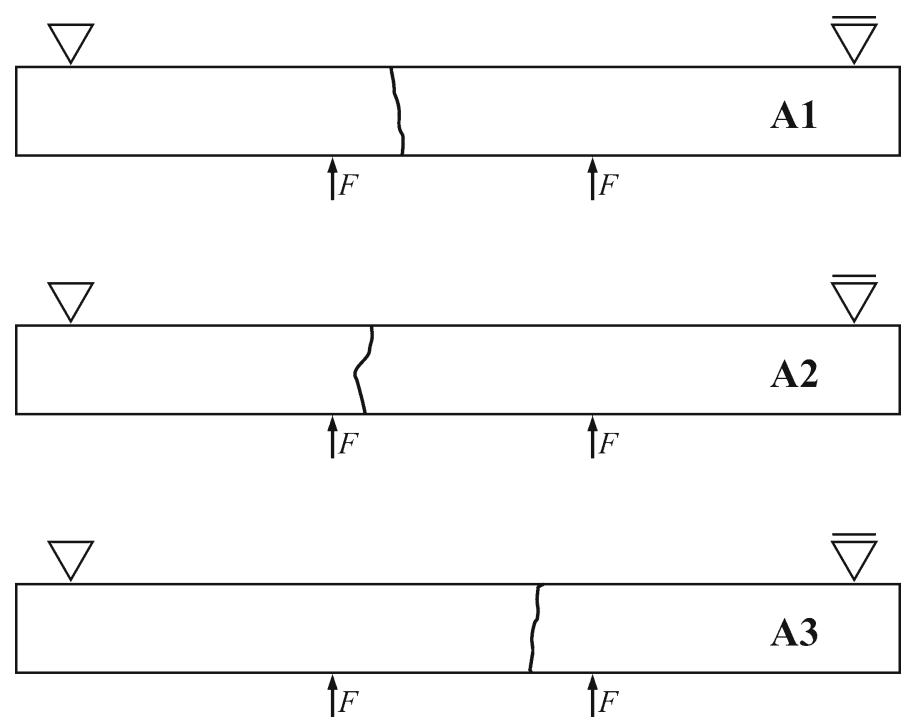

Fig. 2 Location of cracks in plain concrete beams

beams. The cracking moment which decided about load carrying capacity of slightly reinforced concrete beams was greater than cracking moment in concrete members. The difference in failure process connected with developing of flexural cracks in plain concrete and slightly reinforced concrete beams can be observed when comparing the load-deflection curves obtained during the experiment (see Fig. 5). The significantly slower crack formation in slightly reinforced concrete beams resulted in almost four times higher deflection of slightly reinforced concrete beams comparing to the deflection measured in plain concrete beams.

The experimental results have brought the evidence that the presence of reinforcement changes the cracking process and impacts the cracking resistance in reinforced concrete flexural members, even when reinforcement ratio is low. Furthermore, the obtained cracking moment which decided about the load capacity of plain and slightly reinforced concrete beams appeared to be higher in both cases than the theoretical cracking moment calculated on the basis of the theory of elasticity (Eq. 1), as it is recommended in Eurocode 2 [5]. 

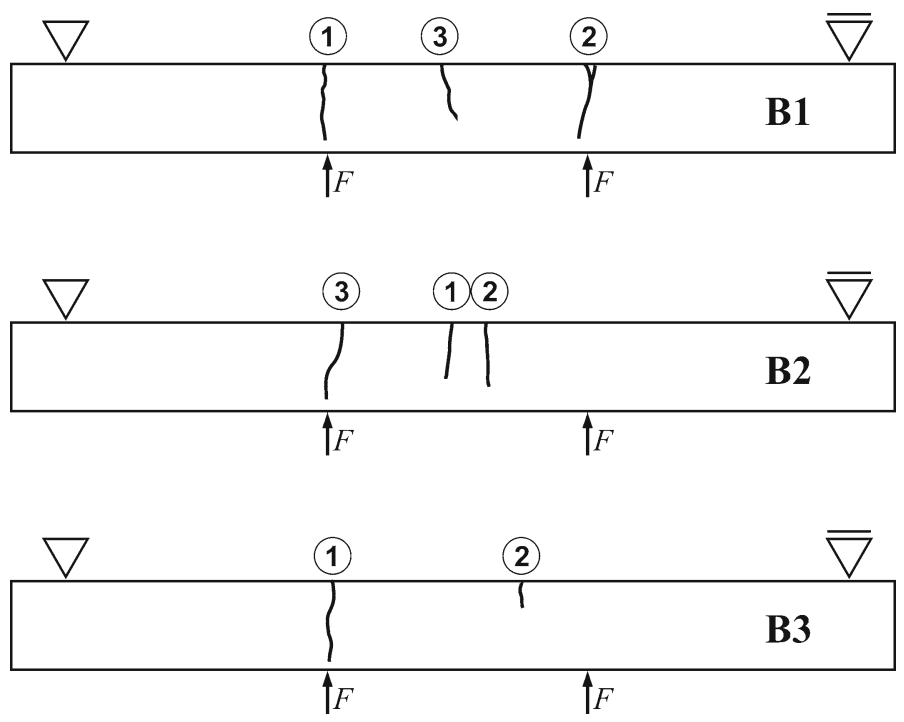

Fig. 3 Location of cracks in slightly reinforced concrete beams

(a)

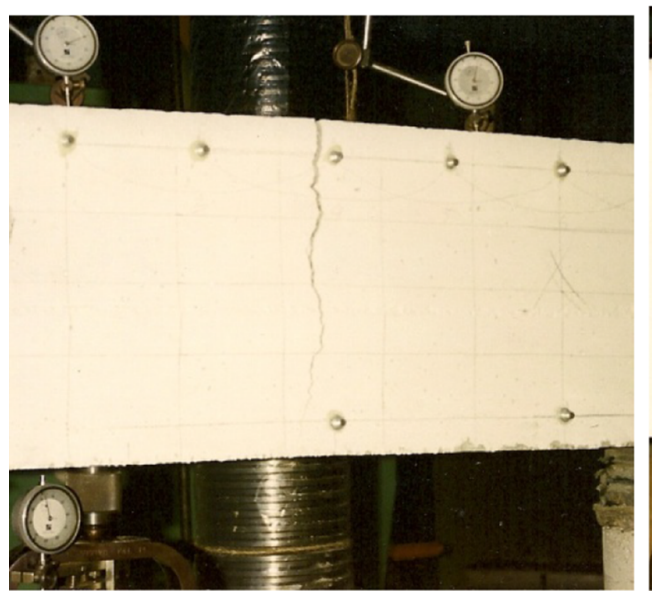

(b)

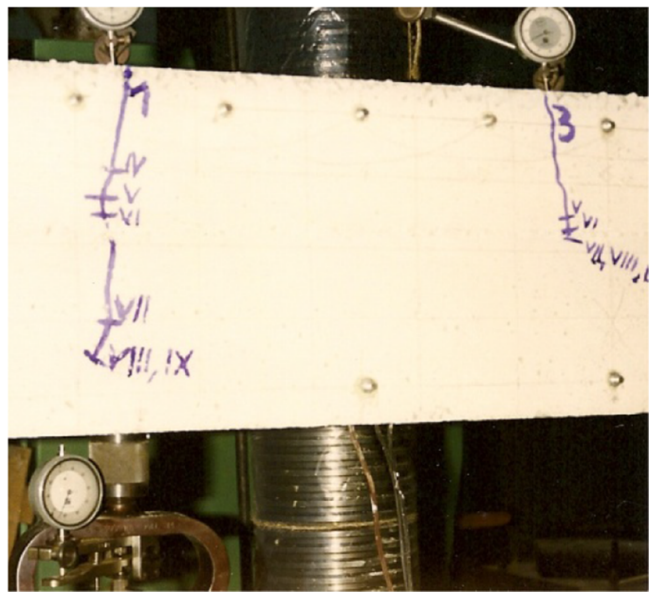

Fig. 4 Photograph of the failure crack in the beam: a A1 and b B1

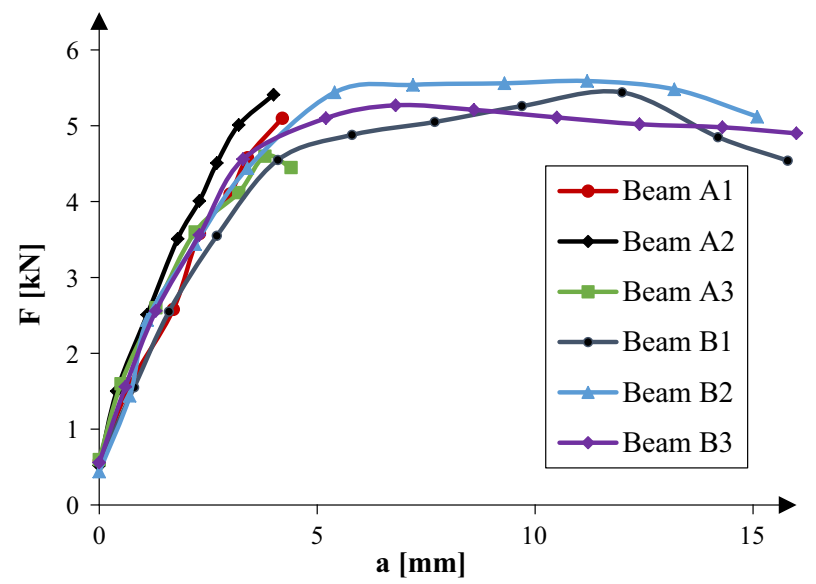

Fig. 5 Load-deflection curves of plain and slightly reinforced concrete beams 


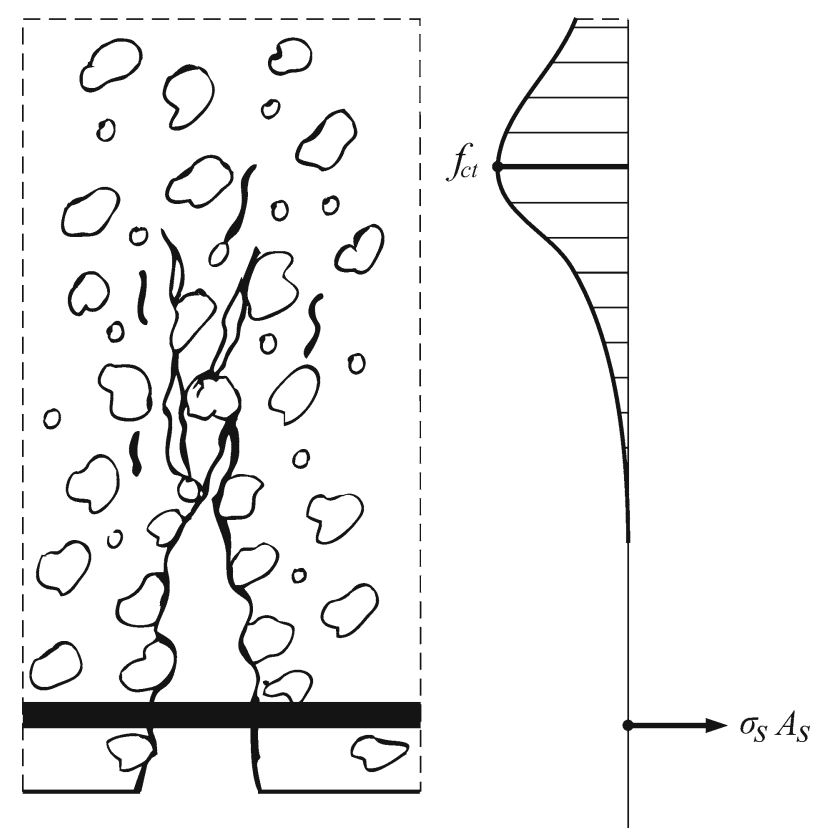

Fig. 6 Formation of macrocrack as a result of bending moment

$$
M_{\mathrm{cr}}^{\mathrm{T}}=f_{\mathrm{ct}} W_{\mathrm{c}}=3.3 \mathrm{kN} \mathrm{m}
$$

where $M_{\mathrm{cr}}^{\mathrm{T}}$ - theoretical cracking moment, $f_{\mathrm{ct}}$-tensile concrete strength, and $W_{\mathrm{c}}=b h^{2} / 6$ - section modulus).

In order to provide better insight into the phenomena associated with tensile fracture of concrete and to investigate the influence of longitudinal steel bars on a crack initiation and propagation in flexural beams, numerical simulations were performed. In numerical calculations made by finite element method, the theory of nonlinear fracture mechanics was implemented and a softening model of tensile concrete was applied. The model was derived from the fictitious crack concept proposed by Hillerborg et al. [12] and improved later by Bažant and Oh [13], Cedolin et al. [14]. The model is based on the assumption that the crack begins to develop in the fracture process zone when the tensile stress achieves the tensile strength of concrete $\sigma=f_{\text {ct }}$. Concrete in the fracture process zone is partially damaged, but it is still able to transfer stress. Strain softening of tensile concrete allowed for transferring smeared crack stress till the crack opening $w$ reaches the critical crack opening $w_{1}$. Cracking process is initiated when existing microcracks start to grow and to coalescence. With further microcracks growth, concrete bonds are broken and the process finally leads to the formation of macrocrack. The basic idea of the macrocrack formation is illustrated in Fig. 6.

For the formulation of the softening law, fracture energy concept is taken into account. Fracture energy $G_{\mathrm{F}}$ is the energy absorbed per unit crack area during crack's formation (Eq. 2). Fracture energy corresponds to the area under the stress crack opening curve $\sigma-w$ obtained as a result of a tensile test of concrete. The preand post-peak behavior of tensile concrete obtained during the test is presented in Fig. 7a, and for practical finite element analysis, it can be simplified by bilinear curves proposed in Model Code [11] (Fig. 7b, c). Such softening characteristic of tensile concrete is recommended in numerical applications $[15,16]$.

$$
G_{\mathrm{F}}=\int_{0}^{w_{1}} \sigma \mathrm{d} w
$$

Numerical calculations were realized using the module APAK0 of the commercial program ALGOR. The module is based on the modified Newton-Raphson method which is applicable to nonlinear analyses. The beam was modeled by three-dimensional, six- or eight-node brick elements in the bulk of the beam and by truss elements in the narrow fracture process zone. The width of the fracture process zone was chosen as $w_{\mathrm{c}}=10 \mathrm{~mm}$ on the basis of the results of the earlier performed numerical analysis [17]. In the fracture process, the concrete in tension was modeled as a nonlinear material according to Model Code (Fig. 7b, c) and uniaxial model was applied for the concrete in compression because a low level of compressive stress was suspected. Outside the process zone the concrete was modeled as an elastic material. The second-order 
(a)

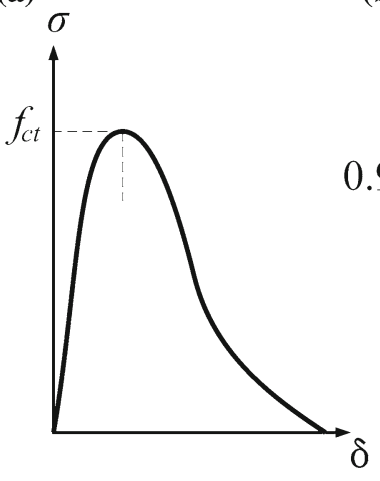

(b)

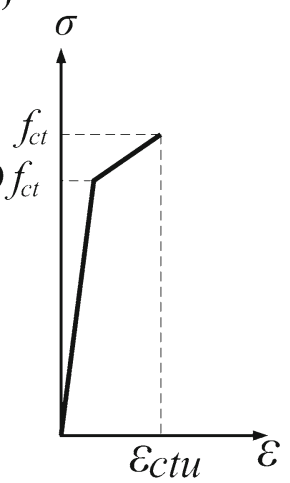

(c)

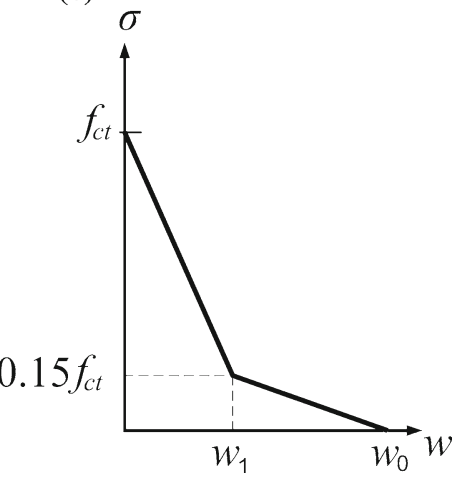

Fig. 7 Tensile concrete characteristic (description in the text)

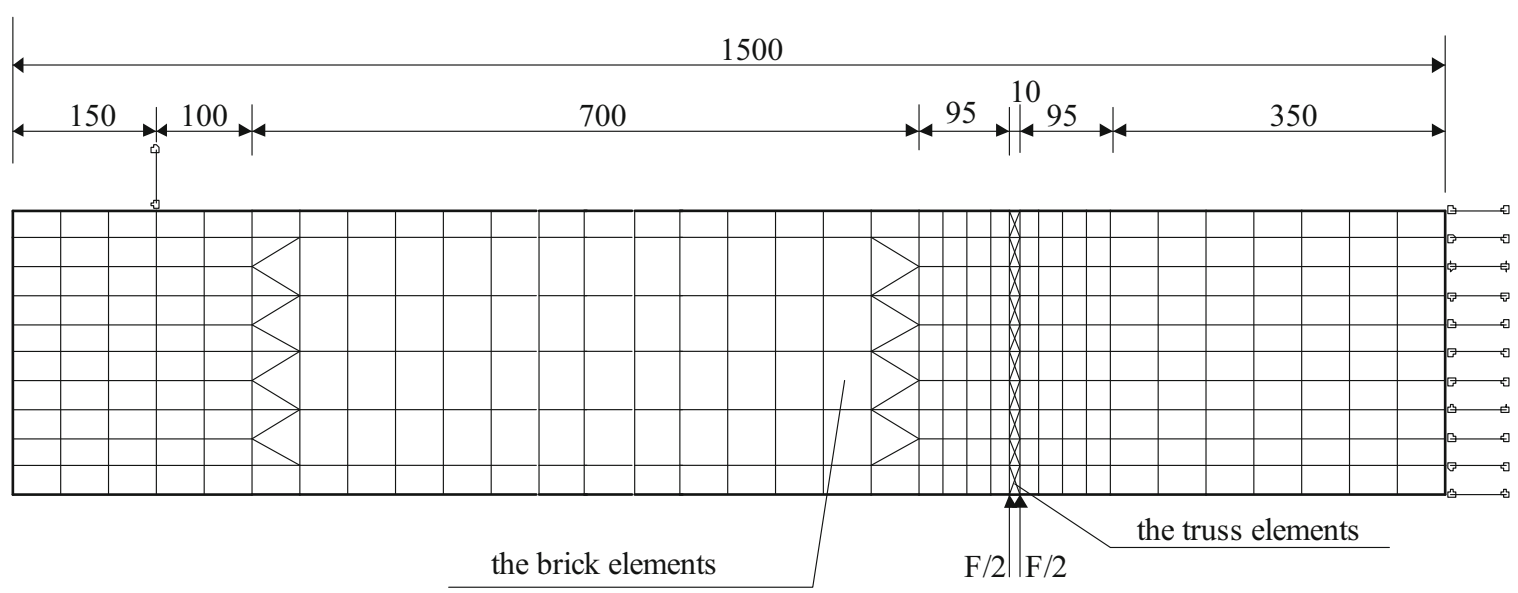

Fig. 8 FEM mesh

integration was used to formulate stiffness matrix for brick elements. Nodes in brick and truss elements had three degrees of freedom. The FEM mesh is presented in Fig 8.

As a result of the FEM calculations, the distribution of normal stress $\sigma_{x x}$ in the fracture process zone was obtained in the plain concrete and the slightly reinforced concrete beam with reinforcement ratio $0.12 \%$ in the following steps of loading (see Fig. 9).

When analyzing the development of normal stress in fracture process zone, it can be observed that the fracture process in beams made of concrete is significantly related to strain softening of tensile concrete. The stress distribution has a linear character till tensile stress reaches the tensile concrete strength $f_{\mathrm{ct}}$ in the extreme upper edge of the tension zone. As concrete is not an elastic and perfectly brittle material, we can observe a progressive cracking process which leads to the macrocrack formation. In the interior of the fracture process zone in deeper fibers, the normal stress reaches the tensile concrete strength, whereas in the upper level of tension zone, the stress decreases down to zero. The influence of strain softening on the crack formation explains why higher experimental cracking moments comparing to the theoretical calculation are obtained during tests on flexural concrete beams with and without reinforcement. Additionally, the presence of reinforcement causes the further increase in cracking resistance in the slightly reinforced concrete beam. The bond between concrete and steel bars influences the stress intensity in the vicinity of reinforcement, and in consequence it slows down the whole process of crack formation. The difference in the mechanism of crack formation is clearly seen when comparing the normal stress distribution in the same load level for plain concrete and slightly reinforced concrete beam (see Fig. 10). The performed numerical simulation permits to explain a less brittle character of the crack formation in slightly reinforced concrete beams comparing to plain concrete beams. 

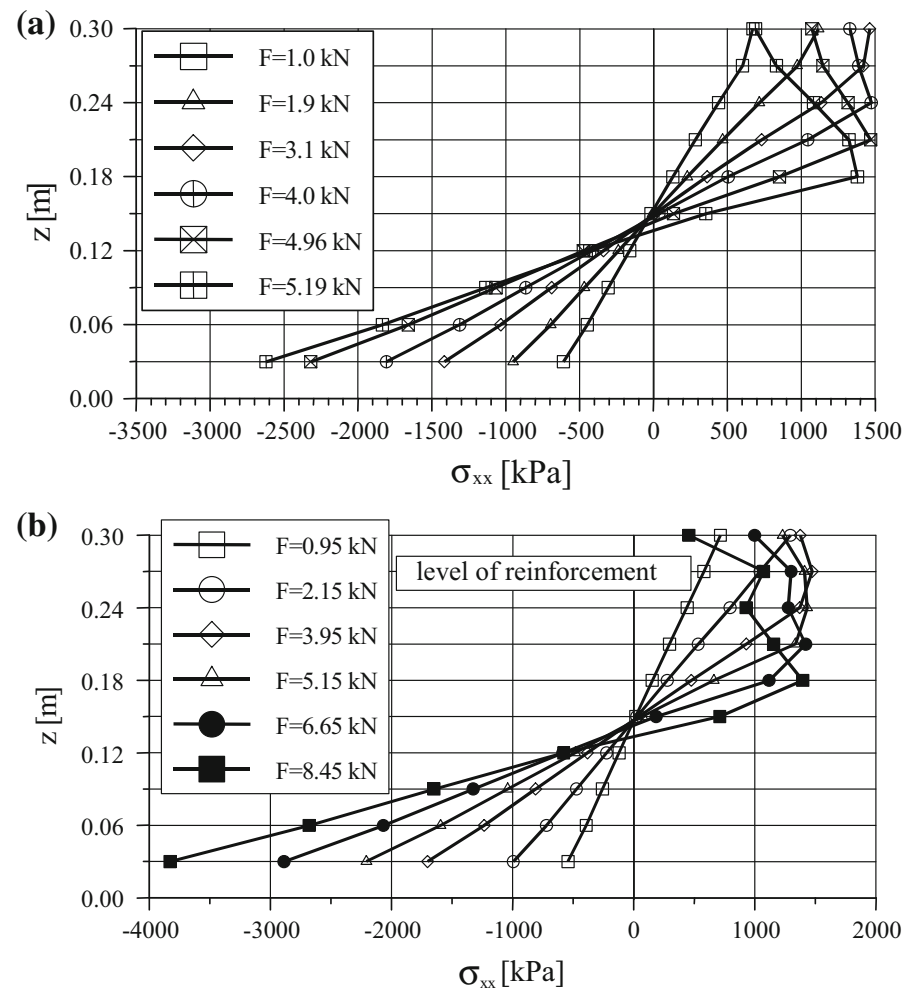

Fig. 9 Normal stress distribution in concrete in the fracture process zone: a plain concrete beam; $\mathbf{b}$ slightly reinforced concrete beam

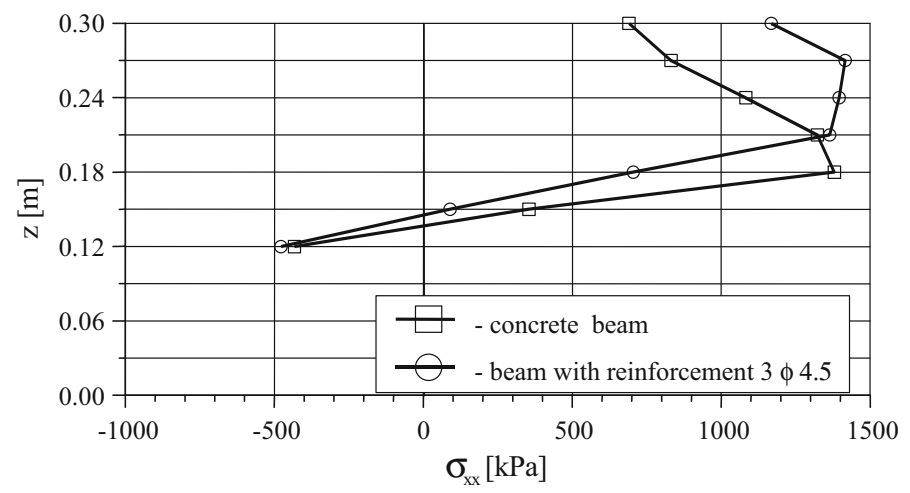

Fig. 10 Comparison of normal stress distribution in the fracture process zone at the same load level

\subsection{Moderately and higher reinforced concrete beams}

In the second stage of the research, the aim of the analysis was to investigate the effectiveness of longitudinal reinforcement in beams of normal and high reinforcement ratio. The experimental investigation was performed on longitudinally reinforced concrete beams in which the reinforcement ratio was $0.9 \%, 1.3 \%$ and $1.8 \%$. It is necessary to noticed that transverse reinforcement was not used in the beams. The beams were tested in a threepoint bending test. The load was applied directly from the testing machine. The beams were $2.05 \mathrm{~m}$ long, and the beams' effective span during the test was $1.8 \mathrm{~m}$. Beams were made of concrete with the maximum aggregate size $D_{\max }=16 \mathrm{~mm}$. The basic concrete properties were tested by standard methods. The compressive strength of concrete was tested on 27 cylinders $\phi 150 / 300 \mathrm{~mm}$, and the obtained mean value was $f_{\mathrm{c}}=35 \mathrm{MPa}$ (standard deviation $s=5.6 \mathrm{MPa}$ ). The tensile strength of concrete was measured on 32 cubes $150 / 150 / 150 \mathrm{~mm}$ at a splitting tensile test. The obtained mean value of splitting tensile strength was $f_{\mathrm{ct}, \mathrm{sp}}=3.5 \mathrm{MPa}$ (standard 

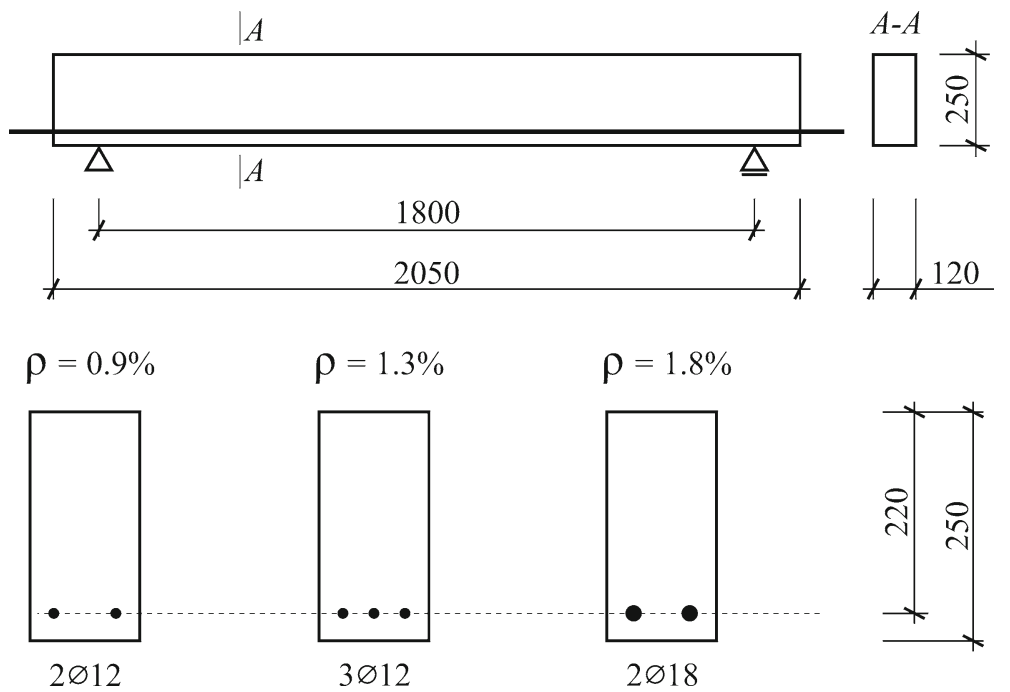

Fig. 11 Beam's geometry and reinforcement

deviation $s=0.4 \mathrm{MPa}$ ), and the axial tensile strength was calculated as $f_{\mathrm{ct}}=0.9 f_{\mathrm{ct}, \mathrm{sp}}=3.15 \mathrm{MPa}$. The modulus of elasticity was measured on 19 cylinders $\phi 150 / 300 \mathrm{~mm}$, and the mean value was $E_{\mathrm{c}}=41400 \mathrm{MPa}$ (standard deviation $s=3650 \mathrm{MPa}$ ). As a longitudinal reinforcement, steel bars of the diameter $12 \mathrm{~mm}$ or $18 \mathrm{~mm}$ were used. The characteristic yield stress of steel bars was $f_{y k}=500 \mathrm{MPa}$. The geometry of the beams and the arrangement of steel bars are presented in Fig. 11. In the paper the selected results of the more comprehensive scientific investigation are presented. More analyses of beams behavior due to shear stress were published in $[18,19]$.

In all tested beams first cracks were initiated at similar load level in the mid-span, and they propagated in the vertical direction. As the load increased, more flexural cracks formed within the mid-span and toward the support regions and the existing vertical cracks became insignificantly wider and deeper. With further increase in loading, vertical cracks situated close to the supports started to change their orientation and become the inclined cracks. The distribution and number of cracks as well as their width and length varied according to the reinforcement ratio. The crack distribution is presented in Fig. 12 where the numbers in circles describe the order of cracks appearing. The photographic documentation of the failure crack in reinforced concrete beams is presented in Fig. 13.

Depending on the reinforcement ratio, different mode of failure was observed in tested members.

The stable growth of vertical cracks was observed in the moderate reinforced beam of reinforcement ratio $0.9 \%$. Such reinforcement effectively prevented against a sudden failure. A slow development of several flexural cracks was observed, and the flexural failure took place. The beam failed at the applied load $F_{\max }=66 \mathrm{kN}$ and the ultimate bending moment reached $M_{\mathrm{ult}}=29.7 \mathrm{kN} \mathrm{m}\left(M_{\mathrm{ult}}=V_{\mathrm{ult}} a\right.$, where $V_{\mathrm{ult}}=F_{\max } / 2$ and $a$ is the distance from the support to the applied load). The full flexural capacity connected with reaching the yield stress in steel bars was achieved.

In higher reinforced concrete beams with the longitudinal reinforcement ratio $1.3 \%$ and $1.8 \%$, after flexural crack formation also the diagonal crack formed in the support zone of the beams. One major diagonal crack developed from the flexural crack due to shear stress which made flexural crack in the shear region to change its orientation and become a diagonal crack. In the tested beams the transverse reinforcement was not used, and therefore, the development of inclined cracks caused the shear, brittle failure. The beams failed soon after the appearance of the main diagonal crack. As shear forces governed the failure in higher reinforced concrete beams, the full flexural capacity due to the applied longitudinal reinforcement was not attained. The longitudinal reinforcement had an impact on the shear capacity of the highly reinforced concrete beams. With the increase in reinforcement ratio, the increase in cracking shear force which caused the appearance of diagonal crack $V_{\text {cr }}$ and ultimate shear force at failure $V_{\mathrm{ult}}$ was noticed. (The cracking shear force was calculated as the half of the applied load at the moment of forming the first diagonal crack $V_{\mathrm{cr}}=F_{\mathrm{cr}} / 2$, and the ultimate shear force was calculated as the half of the applied load at failure $V_{\mathrm{ult}}=F_{\max } / 2$.) In the beam of reinforcement ratio $1.3 \%$, the cracking shear forces was $V_{\mathrm{cr}}=30 \mathrm{kN}$ and the ultimate shear force was $V_{\mathrm{ult}}=37.5 \mathrm{kN}$, whereas in the beam of reinforcement ratio $1.9 \%$, the cracking shear force was $V_{\mathrm{cr}}=37 \mathrm{kN}$ and the ultimate shear force 

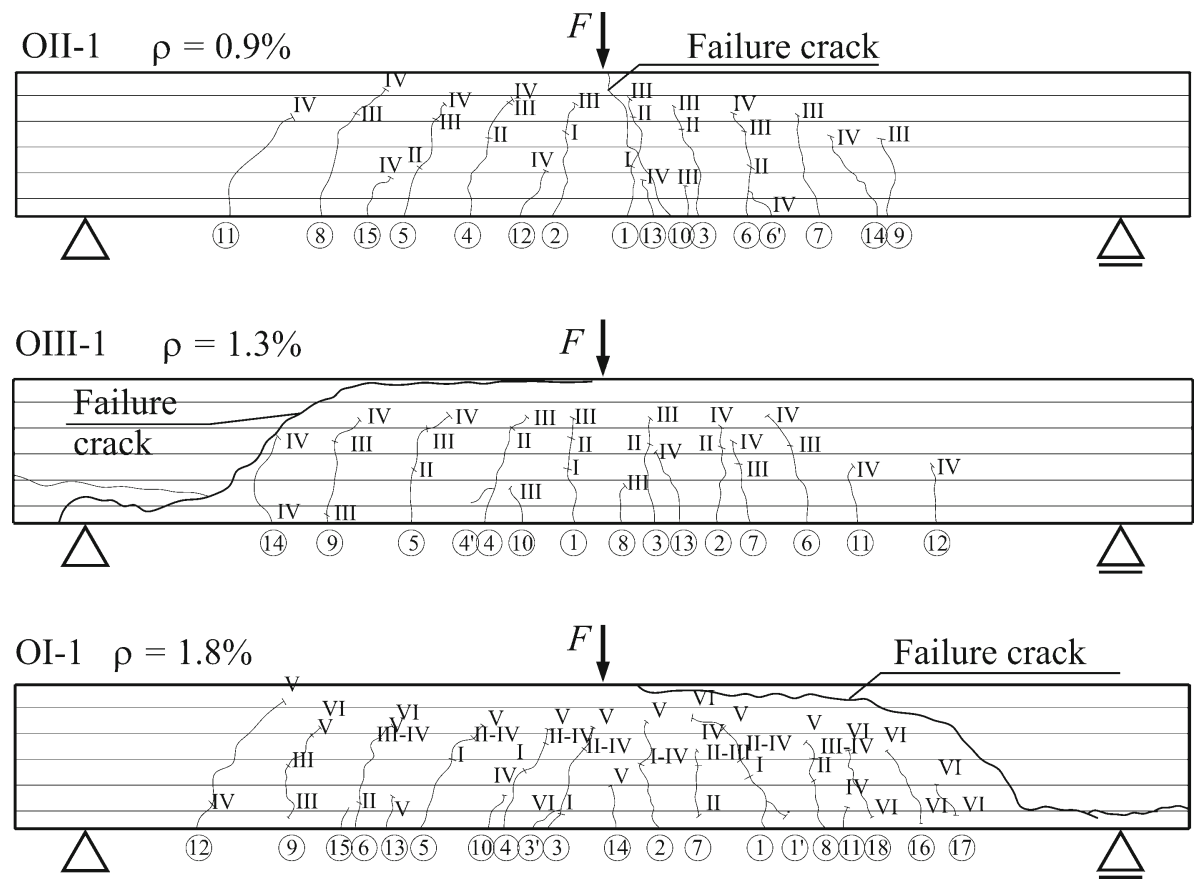

Fig. 12 Crack distribution in the beam of reinforcement ratio $0.9 \%, 1.3 \%$ and $1.8 \%$

(a)

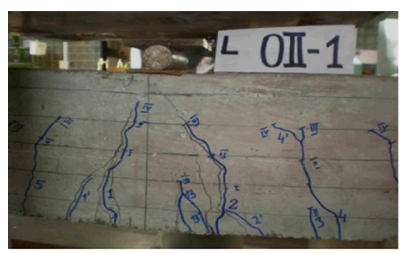

(b)

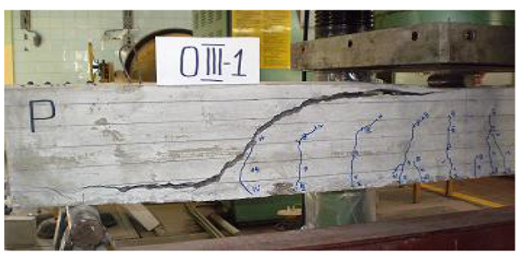

(c)

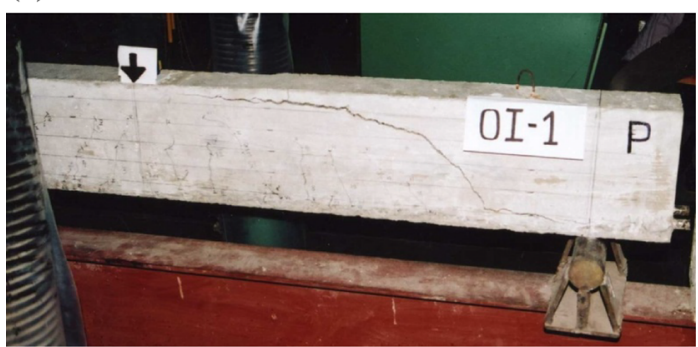

Fig. 13 Photograph of the failure crack in the beam: a OII-1, b OIII-1 and c OI-1 


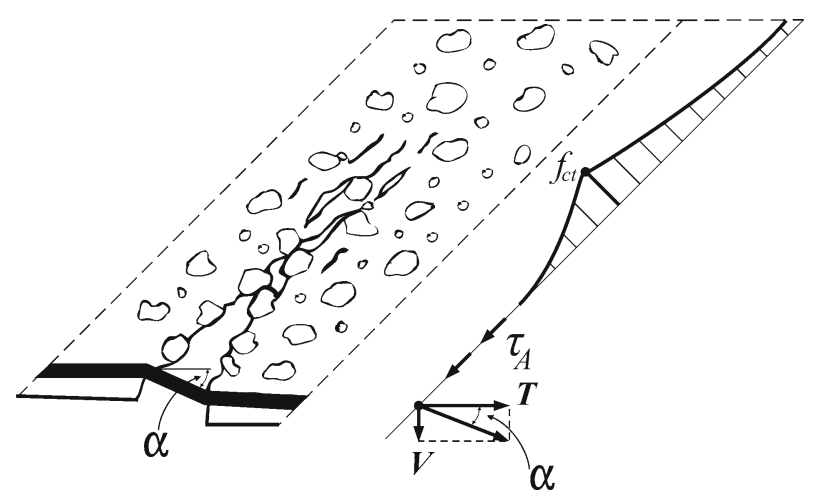

Fig. 14 Formation of diagonal crack

reached $V_{\mathrm{ult}}=43.5 \mathrm{kN}$. It can be observed that ultimate shear forces were higher than cracking shear forces and therefore the failure process caused by inclined cracks did not go in a rapid way.

When analyzing cracking process in the beams, it can be concluded that the slow development of several flexural cracks can be observed up to failure in moderate reinforced concrete beams and in highly reinforced concrete beams, after stabilization of flexural cracking, diagonal cracks appear. The initiation of inclined cracks is influenced by strain softening of tensile concrete, but in the progressive development of diagonal crack such mechanisms as an aggregate interlock and a dowel action of steel bars have appeared to predominate. The increase in shear capacity with the increase in reinforcement ratio shows that dowel action takes more important part in shear transfer in highly reinforced concrete beams. The main mechanisms of stress transfer in longitudinally reinforced concrete beams are illustrated in Fig. 14. When analyzing shear crack propagation, the more advanced model for concrete can be applied, for example, microplane model with relaxed kinematic constraint [20].

\section{Conclusions}

In concrete beams the mode of failure changes according to a longitudinal reinforcement ratio:

- A brittle failure due to the formation of a flexural crack takes place in plain and slightly reinforced concrete beams. The strain softening of tensile concrete is of paramount importance when analyzing crack propagation and failure process in these beams. The cracking moment decides about the load carrying capacity of the beams.

- A stable growth of flexural cracks is possible in moderately reinforced concrete beams. The load carrying capacity is connected with reaching the full flexural capacity and depends on steel yielding or concrete crushing in the compression zone.

- A shear failure which is caused by the development of diagonal cracks predominates in higher reinforced concrete beams without transverse reinforcement. The progressive microcracking appears in the tip of the inclined crack, but strain softening of tensile concrete is not the only mechanism of carrying shear stresses. An aggregate interlock and a dowel action of steel bars contribute more importantly to the development of a failure crack and load carrying capacity.

The performed analysis has confirmed that calculating the cracking moment in flexural concrete members on the basis of the theory of elasticity is not appropriate. In order to obtain results faithful to the real structure behavior, design methods based on fracture mechanics should be applied [21]. The application of fracture mechanics to concrete structures design can also bring the input on developing the effect of structural member size on load carrying capacity (scale effect) [22]. Softening model is very useful to analyze the development of cracks, especially in case of flexural cracks, but when analyzing the propagation of inclined crack, much more complex mechanisms of stress transfer in the crack should be considered.

Longitudinal reinforcement can effectively protect from the unstable growth of flexural cracks when it is designed correctly. Longitudinal steel bars take also a contribution at carrying shear forces, but in beams without transverse they cannot be sufficient enough to resist the unstable growth of inclined cracks. The results of the performed experimental investigation have also shown how important part the transverse reinforcement 
can play in protecting against brittle shear failure, especially in beams with a relatively high longitudinal reinforcement ratio. (Some former analyses of over reinforced concrete beams can be found in [23,24].) The deeper knowledge of the inclined cracks propagation will help to improve the optimal design of transverse reinforcement.

Acknowledgements The work was financially supported by Lublin University of Technology (Grant No. S15/2017).

Open Access This article is distributed under the terms of the Creative Commons Attribution 4.0 International License (http:// creativecommons.org/licenses/by/4.0/), which permits unrestricted use, distribution, and reproduction in any medium, provided you give appropriate credit to the original author(s) and the source, provide a link to the Creative Commons license, and indicate if changes were made.

\section{References}

1. Hillerborg, A.: The theoretical basis of the method to determine fracture energy $G_{F}$ of concrete. Mater. Struct. 18(106), 291-296 (1985)

2. Köksal, F., Şahin, Y., Gencel, O., Yiğit, I.: Fracture energy-based optimization of steel fibre reinforced concretes. Eng. Fract. Mech. 107, 29-37 (2013)

3. Karihaloo, B.L., Nallathambi, P.: Effective crack model for the determination of fracture toughness $K_{I C}$ of concrete. Eng. Fract. Mech. 35, 637-645 (1990)

4. Xu, S., Zhang, X.: Determination of fracture parameters for crack propagation in concrete using an energy approach. Eng. Fract. Mech. 75, 4292-4308 (2008)

5. EN 1992-1-1:2004, Eurocode 2: Design of concrete structures. Part 1: General rules and rules for buildings. CEN, Brussels (2004)

6. Leonhardt, F., Walther, R.: Versuche an einfeldrigen Stahlbetonbalken mit und ohne Schubbewerhrung. Deutscher Ausschu $\beta$ für Stahlbeton Heft 151, W. Ernst, p. 83 (1962)

7. Kani, G.N.J.: Basic facts concerning shear failure. J. ACI 63, 675-692 (1966)

8. Bažant, Z.P., Kazemi, M.T.: Size effect on diagonal shear failure of beams without stirrups. ACI Struct. J. 88, 268-276 (1991)

9. Słowik, M.: The analysis of crack formation in concrete and slightly reinforced concrete member in bending. In: Brandt, A.M., Li, V.C., Marshall, I.H. (eds.) Brittle Matrix Composites, pp. 351-360. Woodhead Publishing Limited, Cambridge (2006)

10. Słowik, M., Nowicki, T.: The analysis of diagonal crack propagation in concrete beams. Comput. Mater. Sci. 52, 262-267 (2012)

11. CEB-FIP Model Code 1990. Bulletin d'information no. 196. First Draft, Lausanne (1990)

12. Hillerborg, A., Modeer, M., Petersson, P.E.: Analysis of crack formation and crack growth in concrete by means of fracture mechanics and finite elements. Cem. Concr. Res. 6, 773-782 (1976)

13. Bažant, Z.P., Oh, B.H.: Crack band theory for fracture of concrete. RILEM Mater. Struct. 16(93), 155-177 (1983)

14. Cedolin, L., Poli, S., Iori, I.: Tensile behavior of concrete. J. Eng. Mech. Div. ASCE 113(3), 431-449 (1987)

15. Rossello, C., Elices, M., Guinea, G.V.: Fracture of model concrete: 2. Fracture energy and characteristic length. Cem. Concr. Res. 36, 1345-1353 (2006)

16. Kwon, S.H., Zhao, Z., Shaha, S.P.: Effect of specimen size on fracture energy and softening curve of concrete. Cem. Concr. Res. 38, 1049-1069 (2008)

17. Słowik, M., Błazik-Borowa, E.: Numerical study of fracture process zone width in concrete members. Arch. Civ. Eng. Environ. 2, 73-78 (2011)

18. Słowik, M., Smarzewski, P.: Study of the scale effect on diagonal crack propagation in concrete beams. Comput. Mater. Sci. 64, 216-220 (2012)

19. Słowik, M.: Shear failure mechanism in concrete beams. Proc. Mater. Sci. 3, 1977-1982 (2014)

20. Ožbot, J., Li, Y., Kožar, I.: Model for concrete with relaxed kinematic constraint. Int. J. Solids Struct. 38, 2683-2711 (2001)

21. Gerstle, W., Bažant, Z.P. (eds.): Concrete Design Based on Fracture Mechanics, vol. SP-134. ACI, Michigan (1992)

22. Bažant, Z.P., Planas, J.: Fracture and Size Effect in Concrete and Other Quasibrittle Materials. CRC Press, Boca Raton (1998)

23. Van Mier, J.G.M., et al.: Strain-softening of concrete in uniaxial compression - Report of the Round-Robin Test carried out by RILEM TC 148-SSC. Mater. Struct. 30(198), 195-209 (1997)

24. Ožbot, J., Li, Y.J., Eligehausen, R.: 3D finite element analysis of over-reinforced beams. In: Karihaloo, B.L. (ed.) Fracture Mechanics of Concrete Structures, pp. 1233-1240. Aedificatio Publishers, Freiburg (1998)

Publisher's Note Springer Nature remains neutral with regard to jurisdictional claims in published maps and institutional affiliations. 